\title{
MOTION STUDIES OF THE LUMBAR SPINE
}

\author{
A Preliminary Report \\ George F. Pennal, Garson S. Conn, Glen McDonald, Gordon Dale and \\ Henry Garside, Toronto, Canada \\ From the Orthopaedic Department, St Joseph's Hospital, Toronto
}

Many methods using flexion and extension radiographs have been developed to study motion of the lumbar spine. Superimposition of the radiographs has been used to determine the range of motion of the entire lumbar spine and at each level. Relative variation in the amount of movement occurring between given vertebrae has been suggested as an indication of pathological change at that level (Begg and Falconer 1949; Tanz 1953; Allbrook 1957; Mensor, Gross and Duval 1957; Aho and Tähti 1957; Jonck and Van Niekerk 1961; Clayson, Newman, Debevec, Anger, Skowlund and Kottke 1962; Lindahl 1966). Measurements of the total spinal convexity in flexion and extension have also been recorded (Jirout 1957, Israel 1959). Other methods of geometric assessment of motion in flexion and extension in normal and abnormal backs have been described (Gianturco 1944; Alvik 1949; Rosenberg 1955; Hoag, Kosok and Moser 1960; Ho 1962). Because of technical difficulties and questionable reliability, few if any of these techniques have found widespread acceptance.

This article describes a practical method of radiographic assessment of lumbar motion in subjects with and without symptoms, and gives the preliminary results. The investigation was concentrated on the lower three levels.

The method employs the superimposition of lateral radiographs taken in flexion and extension to find a point about which motion occurs for each intervertebral level. This should properly be called a "point of zero instant velocity", but we have arbitrarily called it a "point of motion". The concept applies equally well to a single joint or to the complex motion of the spine.

On this basis, if we can find a point of zero instant velocity for an intervertebral level, then all other points moving in the spine may be related to it and compared from patient to patient. In addition, changes in the position of a point of zero instant velocity may reflect changes in the whole or any part of the lumbar spine.

In relating this concept to the study of spinal motion, consideration must be given to the complex anatomy of the spine. It should be recognised that motion at a particular intervertebral level is dependent not only on the disc but also on the state of the apophysial joints and the surrounding muscles and ligaments as well as the neural components. Motion also depends on the inter-relationship of the gross movements usually described in distinct terms as flexion, extension, lateral bending and rotation, which we believe are seldom if ever performed separately. Thus, if a point of motion can be determined for a normal intervertebral level, then variations in this point may reflect changes in function. Comparative analysis formed the basis of this work.

\section{RADIOGRAPHIC TECHNIQUES}

Radiographs are taken with the patient standing side on to an upright Potter-Bucky stand. The focal film distance is 40 inches with the central ray at the L.4-5 level. For ease of superimposition the exposure should produce a film that is somewhat grey.

The patient crosses forearms and puts hands on shoulders. A foam rubber pad is placed between the patient and the stand, between iliac crest and greater trochanter, to provide 
shoulder clearance. A wide canvas belt, fitted to the stand, is tightened round the iliac crest. It holds the patient firmly against the stand and helps to prevent pelvic rotation.

The patient flexes the spine as far as possible, keeping the knees straight and the feet apart

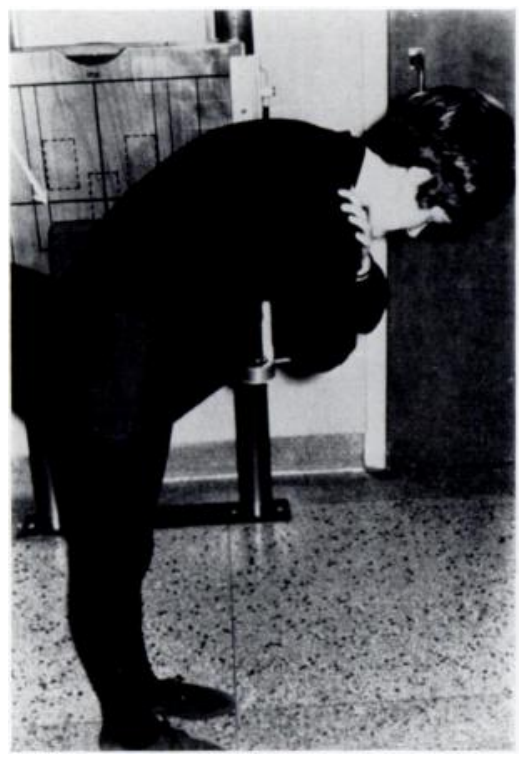

FIG. 1

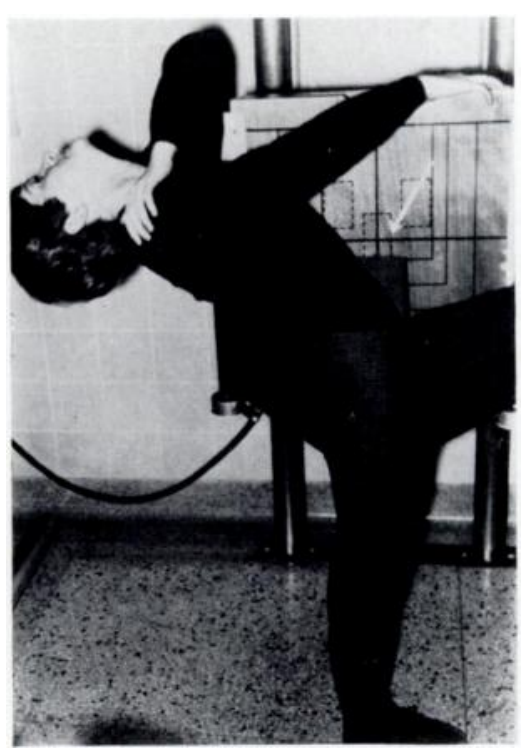

FIG. 2

Figure 1-Position for flexion radiograph. Figure 2-Position for extension radiograph.

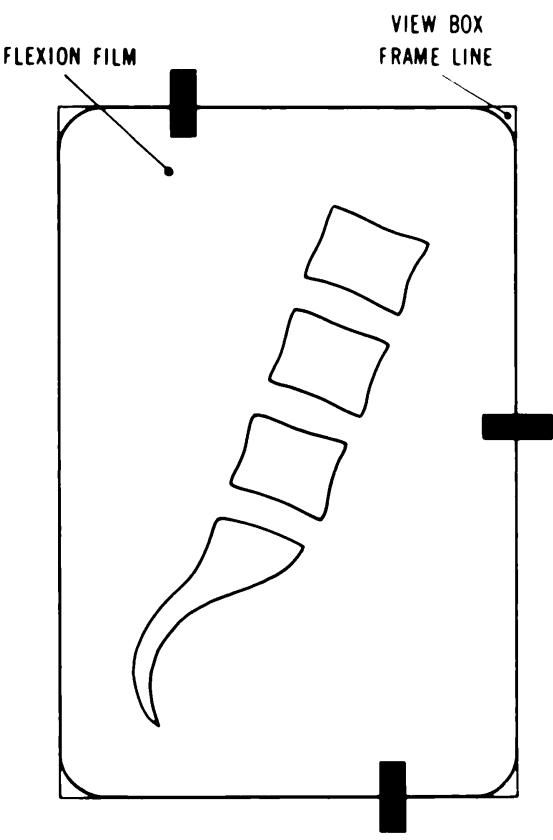

FiG. 3

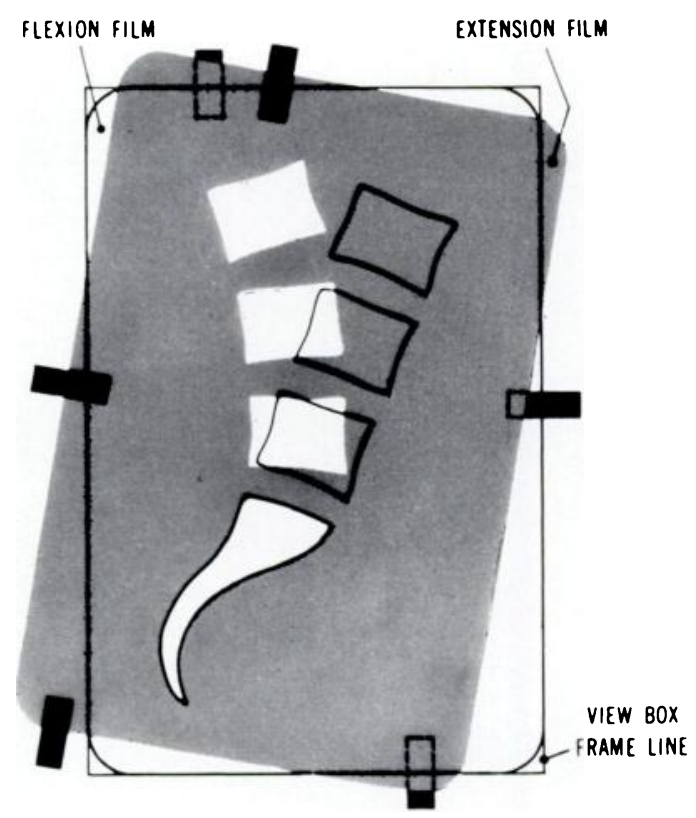

Fig. 4

Figure 3-Flexion film fitted exactly into frame on view-box. Figure 4-Extension film on flexion film. Sacra superimposed exactly.

to shoulder width (Fig. 1). The position is checked from in front and behind to be certain that the shoulders are level and the spine is flexing in the mid-line without rotation or tilting. The flexion radiograph is now taken. 
The patient next bends backwards, grasping the top of the stand with the outside hand for stability (Fig. 2). Any tilt or rotation is corrected. The extension radiograph is now taken.

These two views are essential. Additional views such as antero-posterior and oblique films are an aid to comprehensive assessment.

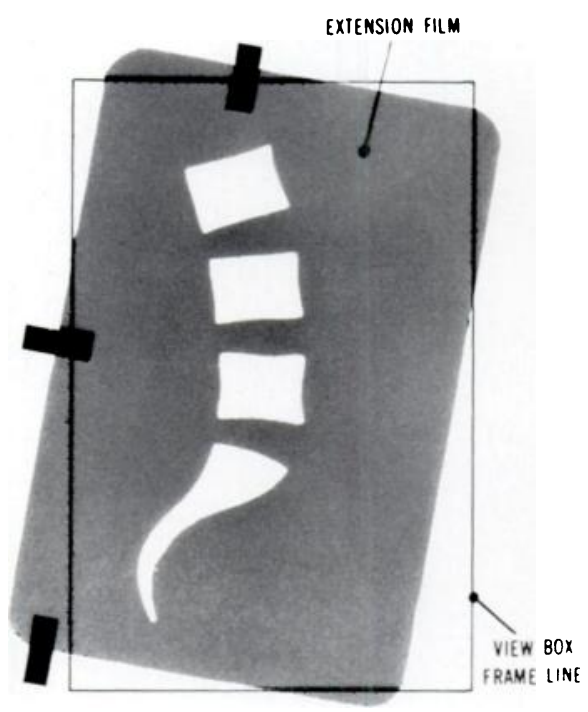

FIG. 5

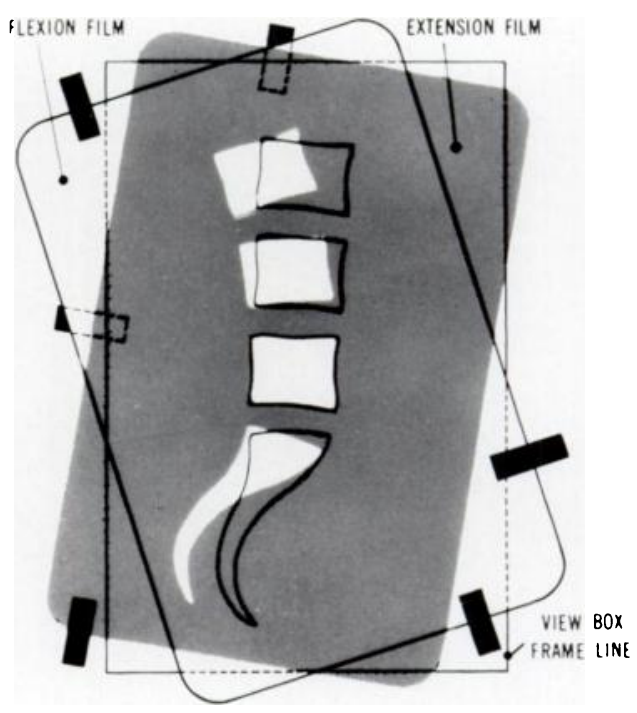

FiG. 6

Figure 5-Flexion film removed. Extension film untouched. Figure 6 Flexion film on extension film-L.5 aligned exactly.

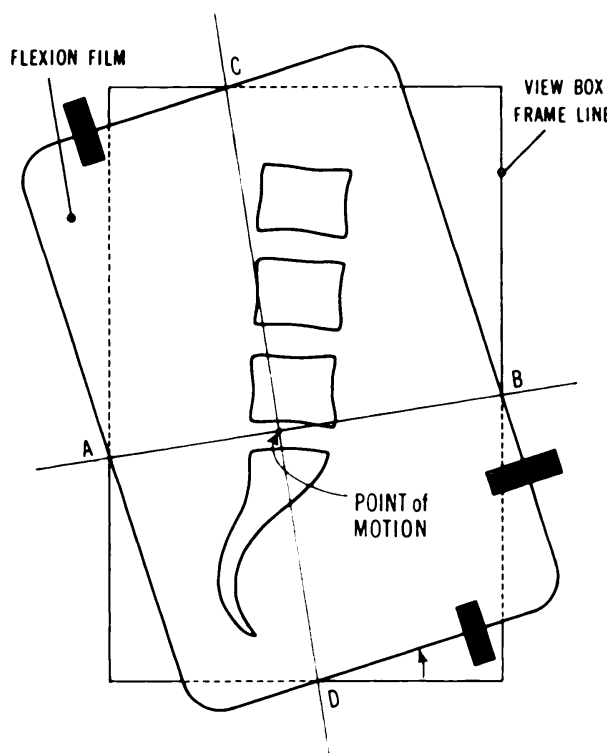

Fig. 7

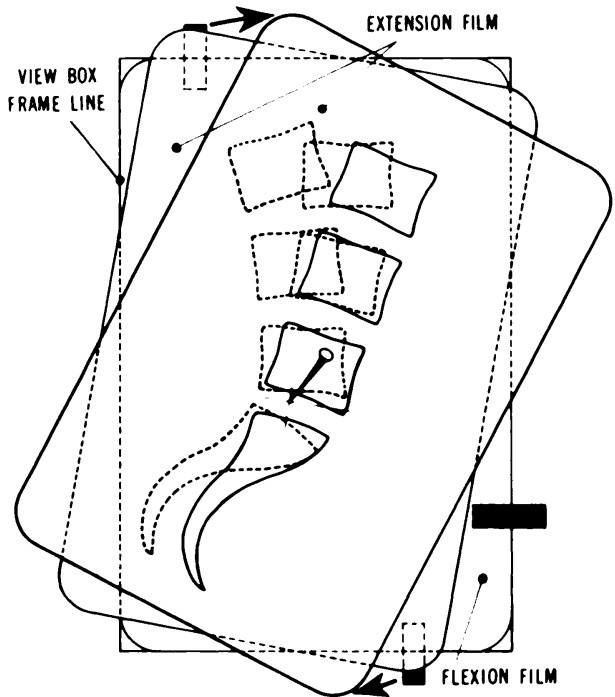

Fig. 8

Figure 7-Extension film removed. Flexion film untouched. Lines drawn to intersect at "point of motion". Figure 8-Extension film on flexion film with sacra aligned. Pin inserted at "point of motion" through both films and the extension film rotated to confirm the alignment of the bodies of L.5.

Determination of the "point of motion"-This requires the superimposition of flexion and extension films. The method was originally suggested by $\operatorname{Dr}$ G. Sutherland while on the 
radiological staff of St Joseph's Hospital, Toronto. The steps will now be described using the L.5-S.1 level as the example. A similar sequence is used to plot the "point of motion" at any other level.

Step 1-The flexion film is placed in a line frame drawn on the glass of a large cool-light viewing box with the anterior aspect of the spine always facing right (Fig. 3). The film is positioned squarely and fixed in place by adhesive tape. In this research project small variations were found in film sizes; to reduce the effects the films were always aligned to the bottom right-hand corner.

Step 2-The extension film is placed on top of the flexion film so that the sacra are exactly aligned (Fig. 4). The extension film is then taped in place.

Step 3-Without the extension film being moved, the flexion film is removed from beneath it (Fig. 5).

Step 4-The flexion film is then placed on top of the extension film so that the vertebra above the disc space under study, in this case L.5, is exactly aligned. The flexion film is then taped in place (Fig. 6).

Step 5-The extension film is removed from beneath the flexion film. The margins of the flexion film now intersect the predrawn frame line at an angle. Lines A-B and C-D are drawn from these points of intersection at the margins of the film. The place where these lines cross on the film is the "point of motion" (Fig. 7). Step 6-To verify the accuracy of the plot, the extension film is

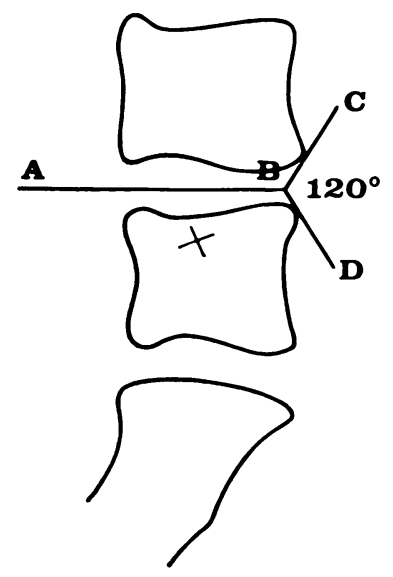

FIG. 9

Use of reference lines to record "point of motion". placed on top of the flexion film so that the sacra are again aligned (Fig. 8). A pin is placed through the extension film into the flexion film at the "point of motion". The extension film is then rotated about the pin to confirm that the body of L.5 on the extension film can be brought to superimpose exactly over the body of L.5 on the flexion film (Fig. 8).

We have found this method of geometric layout relatively simple. With experience, the "point of motion" for the three lower lumbar levels can be determined in approximately ten minutes. One difficulty that may be encountered is insufficient movement in the lumbar spine. The angle at which the last radiograph, the flexion film, crosses the frame should be greater than 5 degrees. If the angle is less than 5 degrees, it indicates that insufficient motion has occurred at the vertebral level being studied. Under these circumstances the point of intersection with the frame is difficult to read accurately and the "point of motion" may be uncertain.

\section{STUDY OF ASYMPTOMATIC SUBJECTS}

To assess the value of the technique in studying the lumbar spine the "point of motion" was determined in a series of clinically normal subjects with no symptoms. One hundred and seven volunteers between the ages of eighteen and sixty years, with no history of back pain or injury and with an apparently full range of spinal movement, were selected from hospital personnel and from patients with upper extremity lesions only (Table I). The "point of motion" was determined at each of the L.3-4, L.4-5 and L.5-S.1 levels in every subject.

The number of discs available for analysis was 321, in 107 subjects; 202, or 63 per cent, were acceptable for study. The reasons for discarding the remaining 119 discs (37 per cent) were either technical or pathological.

Twenty-four discs were not used due to obscure film or failure to position subjects correctly. Twenty-three discs were not used because there were less than 5 degrees of movement at each level, which prevented accurate plotting of the "point of motion". Thus forty-seven discs ( 15 per cent) were rejected for these two reasons.

vol. 54 B, No. 3, AUgust 1972 
When radiographic abnormalities were noted, even if at only one level, all three levels plotted were discarded, because these subjects could not be considered as normal for this study. Thus thirty disc levels in ten subjects were discarded due to various congenital
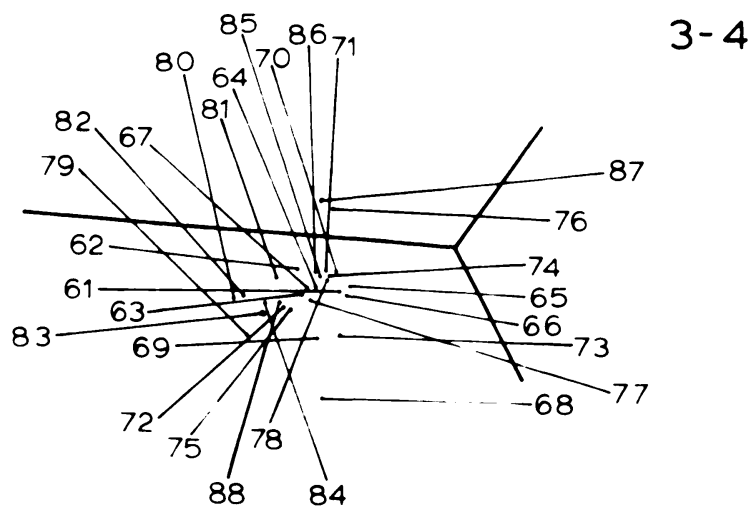

$4-5$
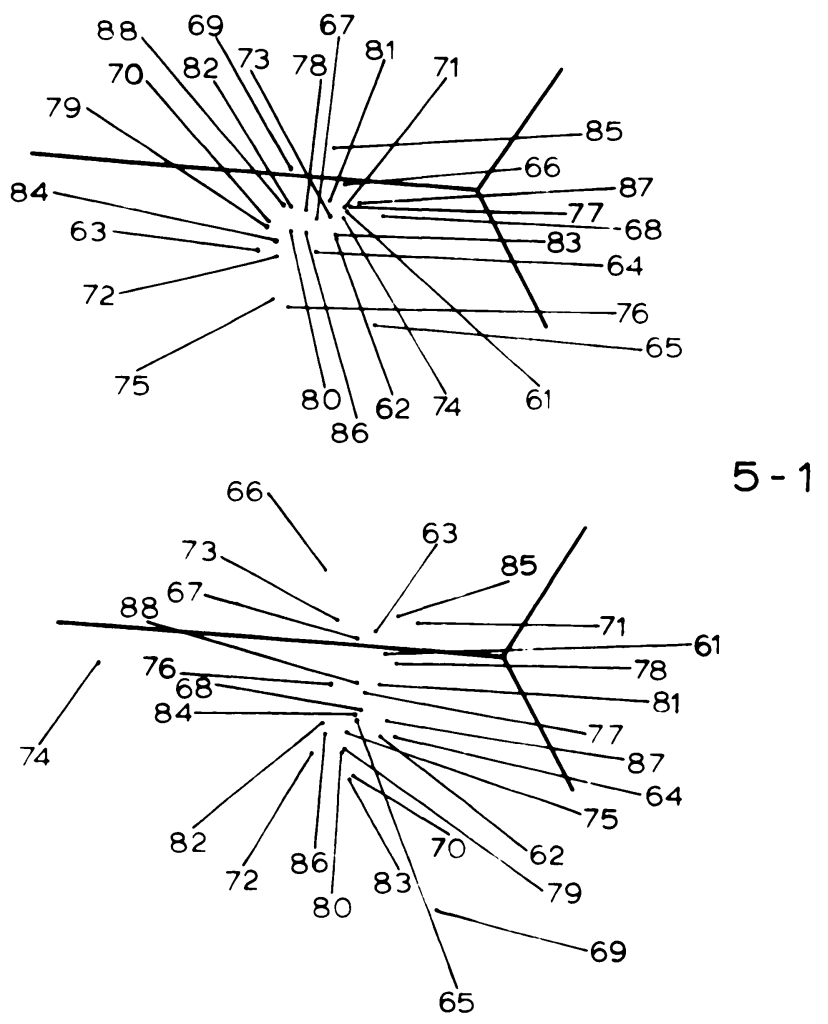

FIG. 10

Typical plastic work sheet accumulation of the "points of motion" plotted from radiographs.

abnormalities, and forty-two disc levels in fourteen subjects were discarded because of pathological changes such as narrowing or osteophyte formation. Table $I$ is an analysis of these asymptomatic subjects. 


\section{PATTERN DETERMINATION}

The "points of motion" at the lower three levels were plotted on the flexion film in all cases. To arrive at a "normal pattern", all the "points of motion" in the 202 disc levels finally accepted as normal were assembled on one master sheet in such a way that vertebrae of different size and shape could be compared.
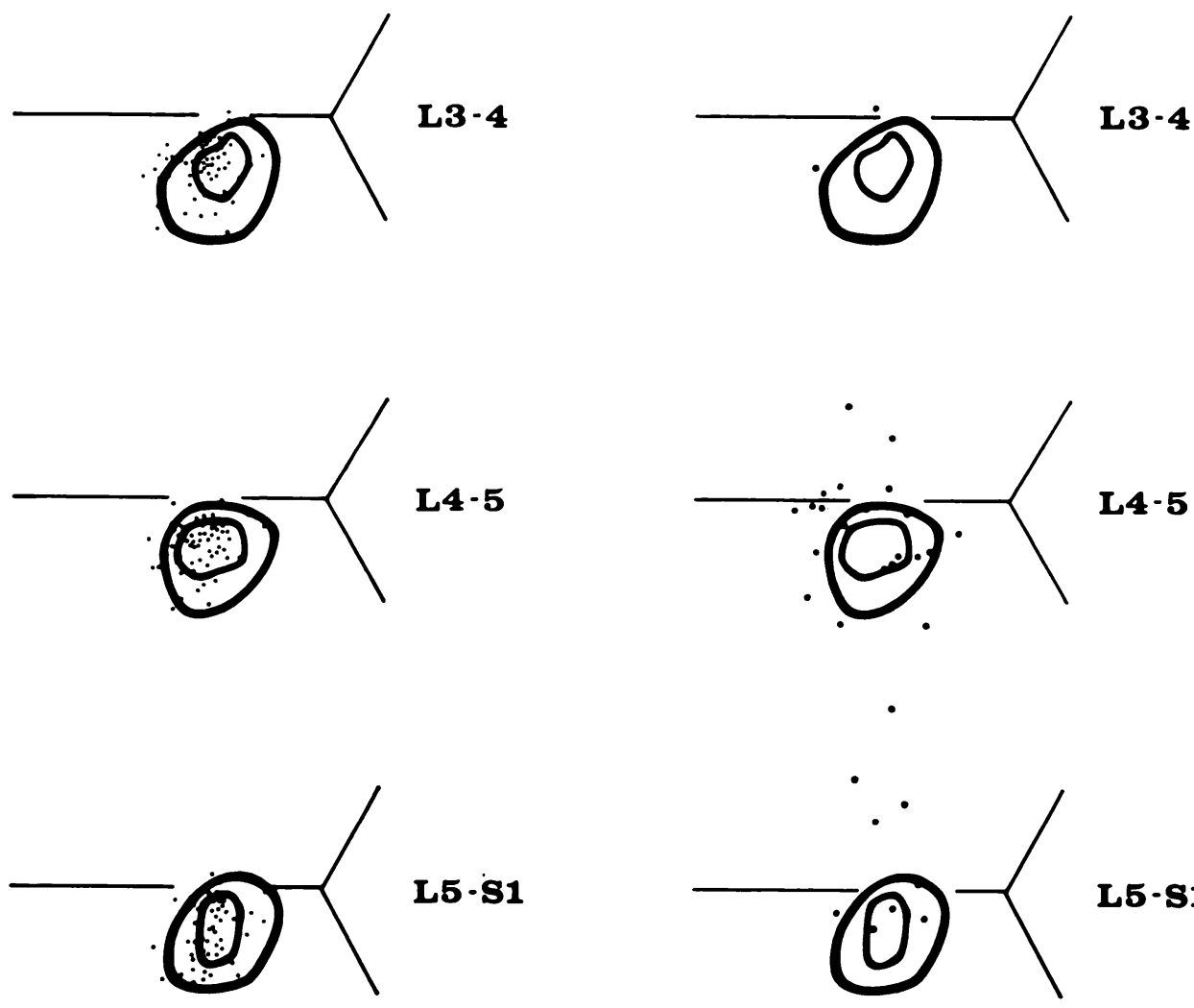

\section{$\mathbf{L 5} \cdot \mathbf{S 1}$}

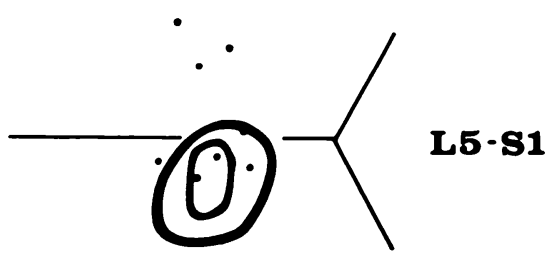

Fig. 11

FIG. 12

Figure 11-“Normal patterns" for the "point of motion" at L.3-4, L.4-5, L.5-S.1, including all the points recorded to form the outlined patterns, in subjects from 18 to 60 years of age. Figure 12-The "points of motion" at pathological disc levels.

Originally a tracing of a lateral view of the lumbo-sacral spine was used. This method is dependent on vertebral body shape, size and position, and because of variations from subject to subject, it was not satisfactory.

To overcome this, a system of geometrically organised reference lines was designed (Fig. 9). They were drawn on a sheet of transparent plastic, which was placed on the films to record the relative position of the "point of motion". In using this device, the horizontal datum is centred in the disc space so that the lines marked A-C and B-D on Figure 9 touch the antero-inferior and the antero-superior corners of the vertebrae above and below, while line A-B bisects the vertical distance between the two vertebrae. By this method, the "points of motion" were transferred from the radiographs to a thin plastic work sheet (Fig. 10).

When all the points had been transferred and recorded, they were found to cluster within a zone at each level, as illustrated in Figure 11. This master sheet is the result of plotting 202 "points of motion" (sixty-seven at L.3-4, sixty-seven at L.4-5 and sixty-eight at L.5-S.1). It is

VOL. 54 B, No. 3, AUGUST 1972 

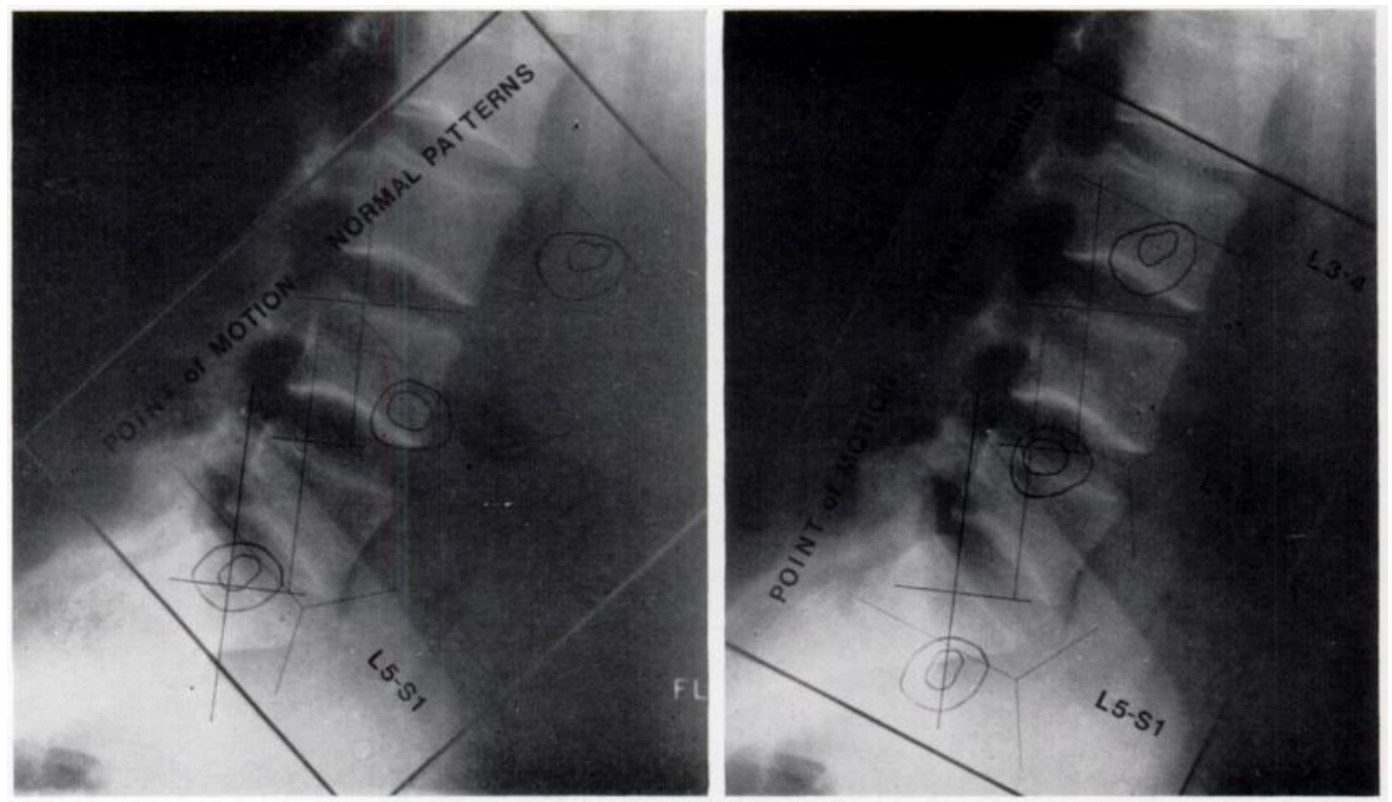

FIG. 13

Transparent instrument with "point of motion" patterns outlined. Left-hand side, applied to L.5-S.1 level. Point of motion in normal zone. Right-hand side, applied to L.4-5 level. Point of motion in normal zone.

marked in two zones: the inner zone represents the greater density $(129$, or 64 per cent), and the outer zone records the most extreme positions (seventy-three, or 36 per cent).

The outlines of these zones have been reproduced on a rigid transparent instrument to be used for clinical assessment by aligning the reference lines as previously described (Fig. 9).

TABLE I

Analysis by Age of 321 Lumbar Disc Levels in 107 Subjects without Symptoms

\begin{tabular}{|c|c|c|c|c|c|}
\hline \multirow{2}{*}{$\begin{array}{c}\text { Age } \\
\text { (years) }\end{array}$} & \multirow{2}{*}{$\begin{array}{l}\text { Number of } \\
\text { patients }\end{array}$} & \multirow{2}{*}{$\begin{array}{c}\text { Discs } \\
\text { accepted } \\
\text { for study }\end{array}$} & \multicolumn{3}{|c|}{ Discs not accepted and reasons } \\
\hline & & & $\begin{array}{l}\text { Technical } \\
\text { reasons }\end{array}$ & $\begin{array}{l}\text { Pathological } \\
\text { changes }\end{array}$ & $\begin{array}{c}\text { Totals } \\
\text { discarded }\end{array}$ \\
\hline $18-20$ & 13 & 33 & 6 & 0 & 6 \\
\hline $21-30$ & 35 & 70 & 14 & 21 & 35 \\
\hline $31-40$ & 21 & 38 & 13 & 12 & 25 \\
\hline $41-50$ & 25 & 42 & 9 & 24 & 33 \\
\hline $51-60$ & 11 & 14 & 4 & 15 & 19 \\
\hline Not known & 2 & 5 & 1 & 0 & 1 \\
\hline Totals & 107 & 202 & 47 & 72 & 119 \\
\hline
\end{tabular}

It is used at the appropriate level on a radiograph to see if the plotted "point of motion" falls inside or outside what we have chosen to call the "normal zone" (Fig. 13).

The "points of motion" were assembled by age in ten-year increments from twenty to sixty years. There was no significant difference in the pattern of any age group. 
TABLE II

Analysis of Seventy-two lumbar Discs in Twenty-four Patients with Symptoms and Disc Disease

\begin{tabular}{|c|c|c|c|c|c|c|c|c|}
\hline \multirow{2}{*}{$\begin{array}{c}\text { Case } \\
\text { number }\end{array}$} & \multirow{2}{*}{$\begin{array}{l}\text { Root } \\
\text { signs }\end{array}$} & \multicolumn{4}{|c|}{ Disc level(s) with abnormalities } & \multicolumn{3}{|c|}{ Position of point of motion } \\
\hline & & Myelogram & Radiograph & Discogram & Discotomy & L.3-4 & L.4-5 & L..5-S.1 \\
\hline 1 & S.1 & L.5-S.1 & L.4-5 & Not done & L.5-S.1 & Normal & Abnormal & Normal \\
\hline 2 & L. 5 & L. $4-5$ & L. $4-5$ & Not done & L.4-5 & Abnormal & Abnormal & Abnormal \\
\hline 3 & S.1 & L.4-5 & L. $4-5$ & Not done & L. $4-5$ & Abnormal & Normal & Normal \\
\hline 4 & L.5-S.1 & L.4-5 & L.5-S.1 & Not done & L.4-5 & Abnormal & Abnormal & Abnormal \\
\hline 5 & Absent & Not done & L. $4-5^{*}$ & Not done & Not done & Abnormal & Abnormal & Abnormal \\
\hline 6 & L.5-S.1 & L.4-5 & L.5-S.1 & L.4-5 & L.4-5 & Technical fault & Abnormal & Normal \\
\hline 7 & Absent & L.4-5 & L.4-5-S.1 & Not done & L.4-5 & Technical fault & Abnormal & Abnormal \\
\hline 8 & Absent & Not done & L. $4-5$ & L. $4-5$ & L.4-5 & Normal & Normal & Technical fault \\
\hline 9 & Absent & Not done & L.4-5-S.1 & L.4-5-S.1 & Not done & Normal & Normal & Abnormal \\
\hline 10 & Absent & Not done & L.4-5 & L.4-5 & Not done & Normal & Normal & Normal \\
\hline 11 & L.5-S.1 & L. $4-5$ & L.4-5 & Not done & L.4-5 & Normal & Abnormal & Abnormal \\
\hline 12 & Absent & Negative & L.4-5 & L.4-5 & Not done & Normal & Normal & Technical fault \\
\hline 13 & L. 5 & L.4-5 & L.4-5 & L.4-5 & L.4-5 & Normal & Normal & Abnormal \\
\hline 14 & L. 5 & L.5-S.1 & L.5-S.1 & L.5-S.1 & L.5-S.1 & Normal & Normal & Normal \\
\hline 15 & L. .5 & Not done & L.4-5 & L.4-5 & L.4-5 & Normal & Normal & Normal \\
\hline 16 & S.1 & L.4-5 & L.4-5 & L.4-5 & L. $4-5$ & Normal & Normal & Abnormal \\
\hline 17 & Absent & L.4-5 & L.5-S.1 & Not done & L.4-5-S.1 & Normal & Abnormal & Abnormal \\
\hline 18 & Absent & L. $3-4$ & L.4-5-S.1 & L. 3-4-5 & L. 3-4-5 & Abnormal & Abnormal & Abnormal \\
\hline 19 & Absent & L.4-5-S. 1 & L.3-4, L . 5-S.1 & Not done & L.4-5-S.1 & Abnormal & Abnormal & Abnormal \\
\hline 20 & S.1 & L. $.5-\mathrm{S} .1$ & L.4-5-S.1 & Not done & L.5-S.1 & Abnormal & Abnormal & Normal \\
\hline 21 & L. 5 & Not done & L.4-5 & Not done & L.4-5 & Normal & Abnormal & Normal \\
\hline 22 & Absent & L. $4-5$ & L.5-S.1 & Not done & Not done & Normal & Abnormal & Technical fault \\
\hline 23 & Absent & L.4-5 & L.4-5 & L.4-5 & Not done & Technical fault & Abnormal & Technical fault \\
\hline 24 & Absent & L. $4-5$ & L.4-5 & Not done & L. $4-5$ & Abnormal & Abnormal & Normal \\
\hline
\end{tabular}

* Spondylolisthesis.

\section{STUDY OF SUBJECTS WITH SYMPTOMS}

Having established apparently normal patterns, we then studied the "points of motion" in subjects with symptoms for whom the clinical records, diagnostic radiographs including myelograms and discograms, and operative findings were available.

Twenty-four cases were studied and the "points of motion" pre-operatively assessed as normal or abnormal. The level, or levels, of pathology were classified and recorded by clinical, radiological and operative findings (Table II).

An abnormal "point of motion" was present in twenty-two (65 per cent) of the thirty-four disc levels in which the pathology was definite. In seven ( 21 per cent) the points fell within the outer range of the "normal" group. In five cases (14 per cent) the points fell within the 

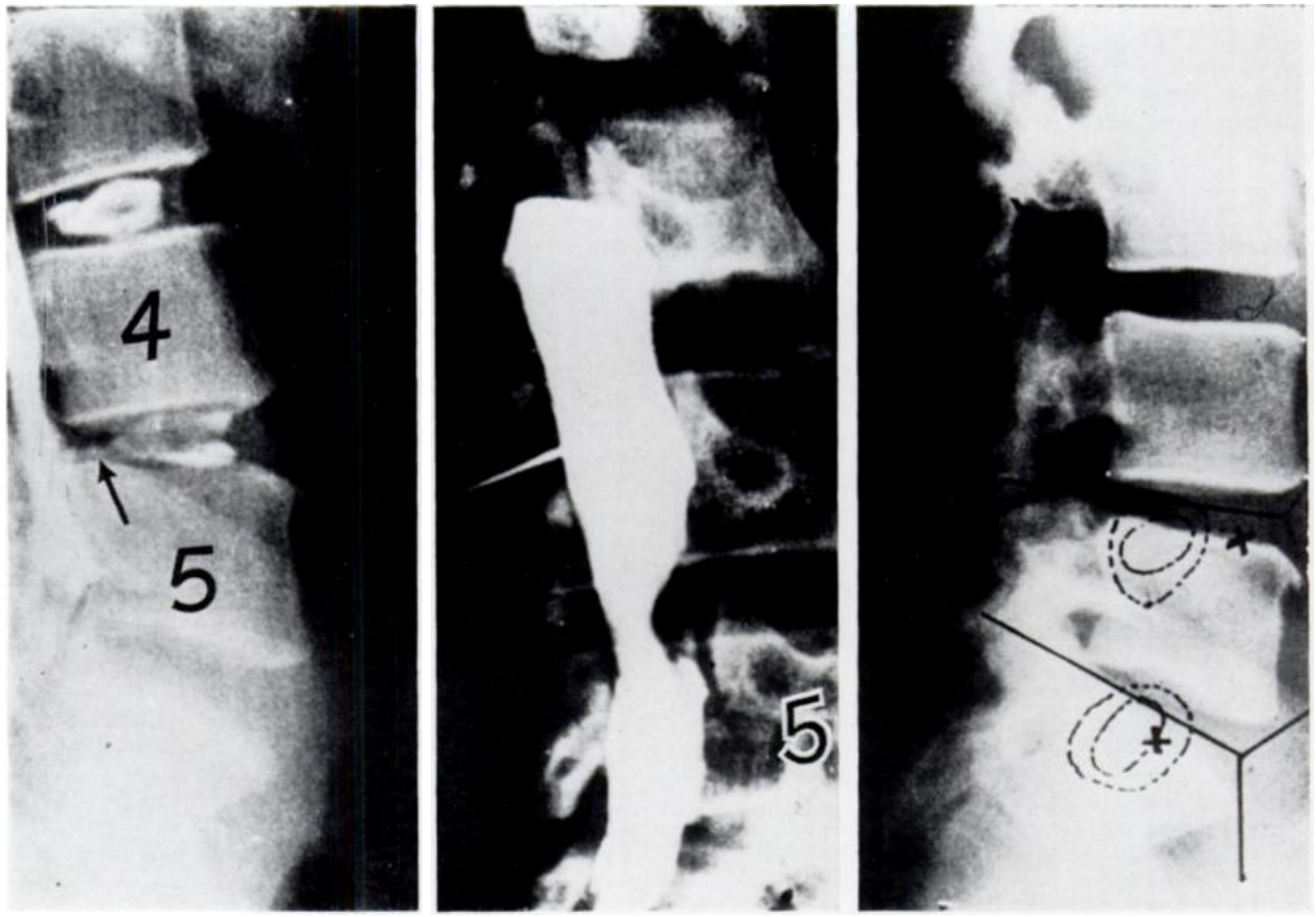

FIG. 14

Case 6-From left to right: abnormal discogram L.4-5: myelographic defect L.4-5; abnormal "point of motion" L.4-5.
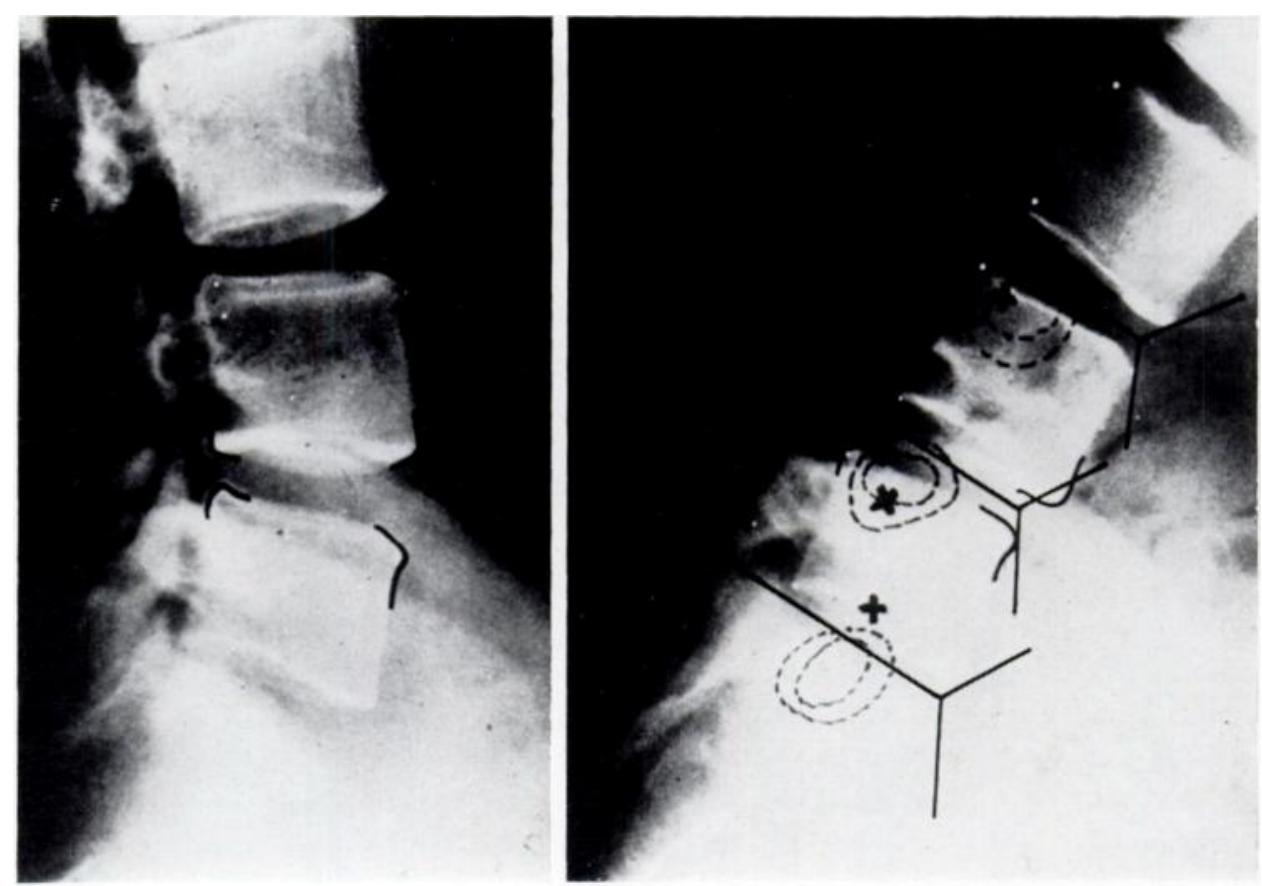

Fig. 15

Case 16-Left: narrowing L.4-5; right: increased movement L.4-5; normal "point of motion" L.4-5. 
most concentrated area of the "normal" zone (Fig. 12). Long term follow-up and zone refinement has been organised in an attempt to find whether or not a "point of motion" that falls in the outer area of the normal zone changes as time passes. In the thirty-one disc levels pre-operatively assessed as normal radiographically, twelve had abnormal "points of motion". These findings are summarised in Table III.

\section{ILLUSTRATIVE CASES (FROM TABLE II)}

Case 6-There was clinical and radiological evidence of abnormality at both the L.4-5 and L.5-S. 1 levels, and an abnormal "point of motion" at the L.4-5 level (Fig. 14). Disc protrusion at L.4-5 was found at operation.

Case 16-This was a case in which the "point of motion" fell within the "normal" zone in the presence of obvious pathology at that level. There was radiographic evidence of slight narrowing of the L.4-5 disc space, with markedly increased motion at that level (Fig. 15). There was also myelographic and discographic evidence of pathology at L.4-5. At operation an obvious disc herniation was found at L.4-5.

TABLE III

Position of Point of Motion at Sixty-five Disc Levels in Twenty-four Patients with Symptoms and with Disc Disease

\begin{tabular}{|c|c|c|c|c|}
\hline \multirow{2}{*}{ Disc level } & \multicolumn{2}{|c|}{$\begin{array}{l}\text { Thirty-four confirmed } \\
\text { pathological discs }\end{array}$} & \multicolumn{2}{|c|}{$\begin{array}{l}\text { Thirty-one radiologically } \\
\text { normal dises }\end{array}$} \\
\hline & $\begin{array}{c}\text { Point } \\
\text { abnormal }\end{array}$ & $\begin{array}{c}\text { Point } \\
\text { normal }\end{array}$ & $\begin{array}{c}\text { Point } \\
\text { abnormal }\end{array}$ & $\begin{array}{c}\text { Point } \\
\text { normal }\end{array}$ \\
\hline L. $3-4$ & 2 & 0 & 6 & 13 \\
\hline L.4-5 & 14 & 8 & 1 & 1 \\
\hline L.5-S.1 & 6 & 4 & 5 & 5 \\
\hline Totals & 22 & 12 & 12 & 19 \\
\hline Percentages & 65 & 35 & 39 & 61 \\
\hline
\end{tabular}

It is difficult to explain the normal "point of motion" found in this patient. It is probable that alteration in motion at a particular intervertebral level depends not only on the integrity of the disc itself but also on the state of the posterior joints. An abnormality at either site could result in an abnormal "point of motion" with the point moving anteriorly from apophysial joint involvement and posteriorly from disc changes, or conversely. Alternatively, when combined pathology exists, the "point of motion" may remain in a normal position. This hypothesis is being investigated by the study of models and by cineradiographic analysis of autopsy spines subjected to motion and stresses.

\section{SUMMARY}

1. This is a preliminary report of an attempt to determine an objective reference point or "point of motion" during flexion and extension of the lumbar spine.

2. The method described uses superimposition of lateral radiographs taken in flexion and extension with the patient standing.

3. In seventy-eight radiographically normal subjects with no symptoms a "point of motion" was determined for each of the lowest three disc levels. At each level these points clustered within a specific zone approximately 2.5 centimetres square. Sixty-four per cent fell within a square centimetre.

vol. 54 B, No. 3, AUGUST 1972 
4. In a comparative study of twenty-four patients with confirmed pathology, the "point of motion" fell outside the larger zone at the level of pathological change in 65 per cent of the disc levels.

5. The determination of the "point of motion" is a special technique for studying spinal motion. Its role as a diagnostic and prognostic aid in assessing patients with back pain is the subject of continuing study.

Support for this project is gratefully acknowledged from the Rehabilitation Foundation of Ontario, St Joseph's Hospital (Toronto) Research Foundation and the James Picker Foundation through the National Academy of Sciences.

\section{REFERENCES}

Ано, A., and TÄнті, E. (1957): Significance of Functional Radiography of the Lumbar Spine in Forward and Backward Flexion. Annales chirurgiae et gynaecologiae Fenniae, 46, 336.

Allbrook, D. (1957): Movements of the Lumbar Spinal Column. Journal of Bone and Joint Surgery, 39-B, 339.

Alvik, I. (1949): Tuberculosis of the Spine. Part II. The Mobility of the Lumbar Spine after Tuberculosis Spondylitis. Acta chirurgica Scandinavica, Supplement 141, 139.

BegG, A. C., and Falconer, M. A. (1949): Plain Radiography in Intraspinal Protrusion of Lumbar Intervertebral Disks: A Correlation with Operative Findings. British Journal of Surgery, 36, 225.

Clayson, S. J., Newman, I. M., Debevec, D. F., Anger, R. W., Skowlund, H. V., and Kottke, F. J. (1962): Evaluation of Mobility of Hip and Lumbar Vertebrae in Normal Young Women. Archives of Physical Medicine and Rehabilitation, 43, 1.

Gianturco, C. (1944): A Roentgen Analysis of the Motion of the Lower Lumbar Vertebrae in Normal Individuals and in Patients with Low Back Pain. American Journal of Roentgenology and Radium Therapy, 52, 261.

Ho, R. W. H. R. (1962): Testing Intervertebral Joint Movement. Journal of the American Osteopathic Association, 61, 635.

HoAG, J. M., Kosok, M., and Moser, J. R. (1960): Kinematic Analysis and Classification of Vertebral Motion. Journal of the American Osteopathic Association, 59, 899, 982.

ISRAEL, M. (1959): A Quantitive Method of Estimating Flexion and Extension of the Spine. Military Medicine, $124,181$.

JiRout, J. (1957): The Normal Mobility of the Lumbosacral Spine. Acta radiologica, 47, 345.

JonCK, L. M., and VAN NiekerK, J. M. (1961): A Roentgenological Study of the Motion of the Lumbar Spine of the Bantu. South African Journal of Laboratory and Clinical Medicine, 7, 67.

Lindaht, O. (1966): Determination of the Sagittal Mobility of the Lumbar Spine. Acta orthopaedica Scandinavica, 37, 241.

Mensor, M., Gross, A. J., and Duval, G. (1957): Mobility Studies of the Lower Portion of the Lumbar Spine in Relation to Low-back Pain. Journal of Bone and Joint Surgery, 39-A, 448.

Rosenberg, P. (1955): The "R"-Center Method, a new method for Analysing Vertebral Motion by X-Rays. Journal of the American Osteopathic Association, 55, 103.

TANZ, S. S. (1953): Motion of the Lumbar Spine. American Journal of Roentgenology, Radium Therapy and Nuclear Medicine, 69, 399. 